\title{
Two Attempts to Extend Economic Model to Socio-Political Issues and Realities
}

\author{
SUlEIMAN I. COHEN ${ }^{*}$
}

\begin{abstract}
Although considered a helpful tool a decade ago, the specification of the development problem in terms of one aim/one nation/one actor avoids the issues and is unrealistic. This paper reports on two models which introduce explicitly social groups as independent actors. The first model examines the formation of income, employment, human resources and satisfaction of basic needs for various social groups. The second model examines the distribution of wealth in a framework which assigns a more dominant role to a particular group on other groups. Applications of the models to four countries are briefly reviewed.
\end{abstract}

\section{THE NEED FOR ALTERNATIVE APPROACHES IN MODELLING DEVELOPMENT}

This paper reports on two attempts to introduce in economic models of a conventional type additional variables specified by social groups.

The central objective of development planning up to the early Seventies has been to maximize national product. The simplifying view prevailed that with the infusion of large enough capital alone, the desired economic growth could be realised. Consequently, planning models of the conventional type were developed by economists aiming at allocating scarce capital to maximize production. The development and planning problem is specified as an allocation problem for one actor having one aim and with one means which can be set to work in alternative uses. To quote one example, the mechanism behind the multisectoral growth model is the allocation of scarce resource capital, say K, on the sectoral products Y's such that the value added $\underline{\Sigma} \mathrm{Y}$ is maximum. ${ }^{1}$

Although considered a helpful tool a decade or two ago, the specification of the development problem in these simplistic terms deforms reality in many ways. A most relevant deformation in the context of this paper concerns the wrong

* The author is associated with the Centre for Development Planning, Erasmus University; and the Netherlands Economic Institute.

${ }^{1}$ See, for instance, the paper by A. Kuyvenhoven in this issue. 
assumption that the economy is organized around one actor. With the one-actor world in mind, it was possible for the conventional modeller to assume off the problem of the distribution of welfare among social groups, the satisfaction of minimum living conditions for major groups of the population, the dominance of one group over others and the role of the state as one among several actors. The conventional model excluded people from its variables.

This paper discusses' two separate but related models which depart from the conventional model described above. The common feature of the two models is that both incorporate several actors and several aims. The two models are to be designated as 1 and 2. In Model 1, the aims go beyond economic growth to include such welfare variables as income, employment, and levels of nutrition, housing, health and education - commonly known as basic needs - specified by social group. In Model 1, the social groups are assumed to be passive in the sense that they do not operate as decision-makers in an explicit way. In Model 2, active roles are assigned to particular social groups in determining the development process. Model 1 has been empirically tested for Korea while Model 2 was applied to India, Chile and Korea. After a brief description of the main features of the models and their structures, a few selected results from each model will be reviewed with the purpose of showing the kind of results which one can expect when following what one may call a 'social-group approach' towards modelling development.

\section{MODEL 1}

\section{Description of Model 1}

The need to develop Model 1 has arisen from the realization that in spite of the reasonable growth rates achieved in different developing countries during the Fifties and Sixties, unemployment and poverty did not decline and in some countries they even increased. By the mid-Seventies, it became increasingly difficult for development models to disregard questions on the distribution of income among population groups. Moreover, employment considerations and higher standards of nutrition, housing, health and education came into the forefront, partly as a result of the promotion given to them through various international organizations. ${ }^{2}$

The distinguishing features of Model 1 can be summarized as follows, while the rest of this section elaborates these features.

(1) Division of total population into groups of people with common interest, usually called social groups, and appraisal of social policies in terms of these groups.

${ }^{2}$ Among the better-known models which introduced one or more of the above aspects are those by Adelman and Robinson [1], CCRP [3], Cohen [4], Correa and Khan [8], Rodgers et al. [13], the on-going applications by Hopkins and V.D. Hoeven [10] to Colombia, Kenya and India, as well as a similar application for Pakistan just starting at the PIDE. The present account of Model 1 draws on the works in Cohen $[4 ; 5]$.
(2) Introduction of welfare indicators relating to each social group in the model. These indicators correspond to what are commonly known as social indicators or aims variables. They may be of a monetary nature (e.g. income per capita) or a non-monetary nature (e.g. employment and standards of nutrition, education, health, etc.).

(3) Incorporation of additional means than are usually present in the conventional models, e.g. allocation of public expenditure to such sectors as housing, health and education by social groups; and explicit planning of the associated sectors with these allocations.

(4) Given the nature of the additional aims and means, Model 1 contains an elaborate mechanism which incorporates relationships with multi-disciplinary contents (e.g. productivity effects of better health, the formation of better health facilities, etc.).

The division of the total population into social groups with more or less homogeneous interests is, as usual, a compromise between theory and availability of data. The data on consumption, expenditure, employment and labour supply for social groups in most of the developing countries do not go beyond a disaggregation into wage-earners, salary-earners and the large group of employers, the self-employed and family workers. In this model, we distinguish these three groups which are denoted by the indices $0=11,0=12$ and $0=13$, respectively. ${ }^{3}$

The monetary and non-monetary aim variables by social group which are incorporated in Model 1 reflect a general consensus usually recurring in various publications of the United Nations. ${ }^{4}$ To start with, Model 1 takes per capita income received by each group to reflect the welfare of that group and as such we have the per capita disposable income of the three groups: $y_{1}^{11}, y_{1}^{12}$, and $y_{1}^{13}$. The second aim, the employment rate, is an aim in its own right and as such we have employment rates for the employee groups: $y_{2}^{11}, y_{2}^{12}$. Our definitions exclude unemployment among the group of employers and the self-employed; this group is assumed to be fully employed. The problem here is that of underemployment rather than of unemployment.

While income and employment can be considered acceptable proxies for the welfare of groups 12 and 13, they may not be sufficient for planning the welfare of the lowest-income group of the population, which coincides in most of the less developed countries with the group of rural and urban wage-earners, identified by

${ }^{3}$ Of course, it is rightly argued that the group of employers, the self-employed and family workers is a very heterogeneous group and cannot have common interests. This group usually contains the richest and some of the poorer parts of the population and its distribution between rural and urban areas is even more subtle. At the time of the application, ready data on the constituents of this group were very scarce for Korea. As Adelman and Robinson [1] show, if time and resources are available, it is possible to gea. As Adelman and Robinf tion of the population.

${ }^{4} \mathrm{cf}$ United Nations [16]. 
group 11 in the model. Due to pressure groups, the policy-makers may not be able to secure what in their view appears to be an acceptable disposable per capita income of the poorest group, $y_{1}^{11}$. Moreover, it may not be possible in the short run to raise the employment rate of this group, $y_{2}^{11}$, to acceptable levels. Under these circumstances, government is assumed to supplement income and employment policies by additional policies aiming at the satisfaction of their nutritional, housing, health and education needs.

Defining low income people as group 11, and noting that nutritional aim should apply solely to that group, the aim variable of average daily per capita intake of calories is relevant as a target variable only if it should refer to group 11 , e.g. $y_{11}^{11}$. Similarly, the per capita number of rooms is assumed to be relevant as a target variable for housing needs only if it should refer to group 11, e.g. $y_{13}^{11}$. For education, we take the primary enrolment ratio, $y_{15}$. Any increase in this ratio, although referring to the whole population, tends to benefit primarily the children of the lowest-income group. With respect to health needs, we have selected the national survival rate as a target variable, $y_{14}$, partly because available data do not make possible the division of health benefits by social groups, but mainly because the characteristic external effects which accompany health levels in the whole nation

\section{Table 1}

Aim Variables in Terms of Social Groups

\begin{tabular}{|c|c|c|c|c|c|c|}
\hline \multirow{2}{*}{$\begin{array}{c}\text { Aim } \\
\text { Variables }\end{array}$} & \multicolumn{5}{|c|}{ Social Groups } & \multirow{2}{*}{$\begin{array}{l}\text { Whole } \\
\text { Nation }\end{array}$} \\
\hline & \multicolumn{2}{|c|}{ Wage-Earners: 11} & Salary - & -Earners: 12 & $\begin{array}{l}\text { Employers, } \\
\text { etc.:13 }\end{array}$ & \\
\hline \multicolumn{7}{|l|}{ Per capita disposable } \\
\hline Income & & $\mathrm{Y}_{1}^{11}$ & & $\mathrm{Y}_{1}^{12}$ & $\mathrm{Y}_{1}^{13}$ & \\
\hline Employment Rate & & $\mathrm{Y}_{2}^{11}$ & & $\mathrm{Y}_{2}^{12}$ & - & \\
\hline $\begin{array}{l}\text { Per capita daily inta } \\
\text { calories }\end{array}$ & of & $\mathrm{Y}_{11}^{11}$ & & - & - & \\
\hline Per capita number $\mathrm{C}$ & rooms & $\begin{array}{r}Y_{13}^{11} \\
\end{array}$ & & & & \\
\hline Survival rate & & & & & & $\mathrm{Y}_{14}$ \\
\hline $\begin{array}{l}\text { Primary school enro } \\
\quad \text { rate }\end{array}$ & nent & & & & & $\mathrm{Y}_{15}$ \\
\hline
\end{tabular}

make it more desirable to formulate this aim for the whole nation. ${ }^{5}$ Aim variables defined in terms of social groups in Model 1 are presented in Table 1.

The introduction of these aim variables in the model requires the incorporation of suitable meaus. The model contains a large range of elements which a government can consider under its full or partial control but our analysis is concentrated on just budgetary instruments which are either instruments of revenues, in the form of direct taxes and others, or instruments of government expenditure in the form of current allocations to the various sectors carrying the index $\mathrm{g}=1, \ldots, 18$; and public investment denoted by ZINV. These control variables are reported in Table 2.

Table 2

Control Variables by Social Groups

\begin{tabular}{|c|c|c|c|c|}
\hline \multirow{2}{*}{$\begin{array}{c}\text { Control } \\
\text { Variables }\end{array}$} & \multicolumn{3}{|c|}{ Social Group } & \multirow{2}{*}{$\begin{array}{l}\text { Whole } \\
\text { Nation }\end{array}$} \\
\hline & Wage-Earners: 1 & $\begin{array}{c}\text { Salary } \\
\text { Earners: } 12\end{array}$ & $\begin{array}{l}\text { Employers } \\
\text { etc.:13 }\end{array}$ & \\
\hline Direct Tax Levy & $\mathrm{Z}^{11}$ & $Z^{12}$ & $Z^{13}$ & - \\
\hline Other Revenue & - & - & - & ZIND \\
\hline Food Subsidies & $\mathrm{Z}_{11}$ & - & - & - \\
\hline General Allocation & - & - & - & $Z_{12}$ \\
\hline Rent Subsidies & $\mathrm{Z}_{13}$ & - & - & - \\
\hline Health Allocations & - & - & - & $\mathrm{Z}_{14}$ \\
\hline Primary Education Allocation & - & -- & - & $Z_{15}$ \\
\hline Secondary Education Allocation & - & - & - & $\mathrm{Z}_{16}$ \\
\hline Higher Education Allocation & - & - & - & $Z_{17}$ \\
\hline Training-on-the-job Allocation & - & - & - & $Z_{18}$ \\
\hline Public Investment & - & - & - & ZINV \\
\hline
\end{tabular}

${ }^{5}$ From a technical point of view, it is sometimes questioned whether it is meaningful at all to consider the above aims separately, as they are dependent on income. We think it is essential. In the first place, the levels of these aims are only partly dependent on the levels of income. More importantly, an exclusive reliance on income is not sufficient for solving the poverty problem, but has to be supplemented by policies relating to physical and social needs. In addition, public allocations-in-kind to the above ends, in comparison to direct income transfers, are usually more effective in reducing poverty. 
In order to relate cuuses and effects of the introduced aim and mean variables, it is useful to describe briefly the type of model we employ. We develop a combined model which integrates the input-output and macro-economic models into one single consistent equation system. ${ }^{6}$ Ten sectors have been distinguished whereby the educational sectors required as comprehensive a treatment as the non-educational sectors within the input-output framework. In addition to the demand for and supply of labour by skill types, the model maps the demand for and the supply of labour by social groups. Remunerations by type of labour depend partly on average productivities of the concerned labour group and partly on the gap between demand for and supply of the concerned labour group. Income of the group of employers etc. is obtained as residual. The levels of the income of the social groups determine how much of each good or service is consumed privately. This private consumption, together with the allocations of public expenditures, is a major determinant of the final demand and production by sector. As a result, the circular formation of the distribution of income, consumption, production and employment is obtained. See Chart 1.

Another category of aims and means is related to the satisfaction of (higher) nutritional, housing and basic education levels for the poorest social groups, $\mathrm{y}_{11}^{11}$ $y_{13}^{11}$, and $y_{15}$ respectively, and (better) health levels for the whole nation, $y_{14}$. Regarding cause-effect relationships following the incorporation of these variables, it should be recognized that it is unlikely that a comprehensive formulation of the causes and effects of higher levels of nutrition, housing, health, education, working capacity, etc., will ever be achieved partly because a great deal of the present evidence on the involved cause-effect relationships is too complex or too particular in nature to permit an aggregate treatment, and partly because of uncertain evidence on other relationships and their form. These limitations apart, the model attempts in its own way to incorporate relationships which give the formation of the newly introduced aim variables as well as relationships which specify their influence. In order to avoid ambiguities, it is necessary to identify the relationships which are commonly accepted in various disciplines as well as such of them as are taken up in Model 1.

In Table 3, we present the complex cause-effect relationships of nutritional, housing, health and educational levels of a population and the quantity of work done by its members in a very simple but operational form. The table gives the direct effects of indicators of the columns on those of the rows. Indirect effects do not appear explicitly but they can be seen from the table. For example, effects of better nutrition, the educational state and the ability of the child to learn are enhanced, and higher educational qualities raise working efficiency after the elapsing of a schooling lag. Therefore, better nutrition leads to higher working efficiency in future. The incompleteness of Table 3 need not bother us at the moment, since

${ }^{6}$ The potential of combined models in development planning has been suggested by a number of economists. See Fisher et al. [9].

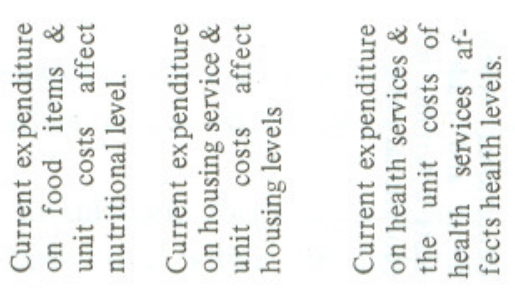

ॠ $\approx$

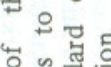


Table 3-Continued

Dependent

Independent Indicators

Indicators

Nutrition level

Housing level
Health level
Private expenditure and public allocations
Educational state

Malnutrition retards the mental \& physical growth of poorly fed children \& diminishes their ability to learn.
Better housing conditions contribute towards higher rates of attendance and attainment in schools.
Better health condi-

Nutrition affects manpower inputs.

The input of calories largely determines the output of energy in human physiology. Malnutrition in the form of low levels of calorie consumption restricts the worker's productivity. tions improve rates of attainment in schools; low morbidity rates allow regular school attendance. Low morbidity rates permit school completion.

Education of the parents stimulate the attainment of higher educational standards of the children.

If a worker feels more satisfied as a result of improved housing he will work more efficiently on the job.

1. Better health conditions raise working efficiency. Low morbidity rates save on absence from work.

2. Low mortality rates increase manpower supply.
1. Higher educational qualities raise working efficiency \& save on working time.

2. Education enrolments will cause the expansion of the supply of manpower types after various lags.
Educational expenditure and student costs determine the educational state. 
obtain through input-output relationships the production of non-educational and educational sectors.

Attention can now be directed to the relations which determine the formation of manpower. The resources available to the educational sectors determine enrolment flows and the future supply of labour types. These are translated into supplies by social groups. Demand for labour by skill type is determined by the production of the educational and non-educational sectors. This demand is mapped later by social groups. Finally, employment rates are defined in terms of the supply of and demand for manpower by social group, $\mathrm{y}_{2}^{11}$ and $\mathrm{y}_{2}^{12}$.

The model is extended to income formation by social groups. Labour productivity and employment rates determine the gross income of wage-earners and salaryearners. The income of the group of employers is obtained as a residual. After deduction of taxes we get disposable income by social groups. Inserting these disposable incomes in the consumption functions we obtain the private components of final demand which happens to be the starting point from which we began at the top of the chart. The chart is now extended to account for (i) the formation of indicators describing basic needs, and (ii) their effects on the rest of the model.

First, a particular indicator, e.g. the one in the last row of the chart, depends on the portion of private consumption and government allocations devoted to it.

Secondly, the effects of higher standards of living are reflected in an increase in the productivity of workers. This would result in decreased requirements of manpower. Besides, health levels, in the form of survival rates, also play a role in influencing the supply of students and manpower, (see the arrows rising upwards in the chart).

\section{Uses of Model 1}

In conformity with the accepted uses, the analytical form of the model treated aim variables as unknown, and instrument variables as given. The complete policy form is usually described as the reverse, with all aim variables taking the form of fixed targets and instrument variables becoming unknown.

Now an interesting situation arises when a model contains a substantial number of aim variables which need to be fixed. We need to know whether there exists a certain meaningful ranking that can tell us which specific aim variables should be fixed first, and which others should be fixed later.

The answer to this question runs along the following lines. Granted for the moment that there are no political preferences which dictate the form in which the model is to be used or which specify the aim variables that have to be fixed before others. We may inquire, on purely technical grounds, into the most logical selection procedure. It is a commonsense argument that in such a situation we should put side by side the matrix structures of a number of conceivable alternative policy forms and select the one which possesses the simplest structure to serve as a starting point. It logically follows also that after starting with the simplest structure one should
Chart 1

The Abbreviated Structure of Model 1

\begin{tabular}{l}
$\begin{array}{c}\text { Controllable } \\
\text { variables }\end{array}$ Endogenous Variables \\
\hline
\end{tabular}

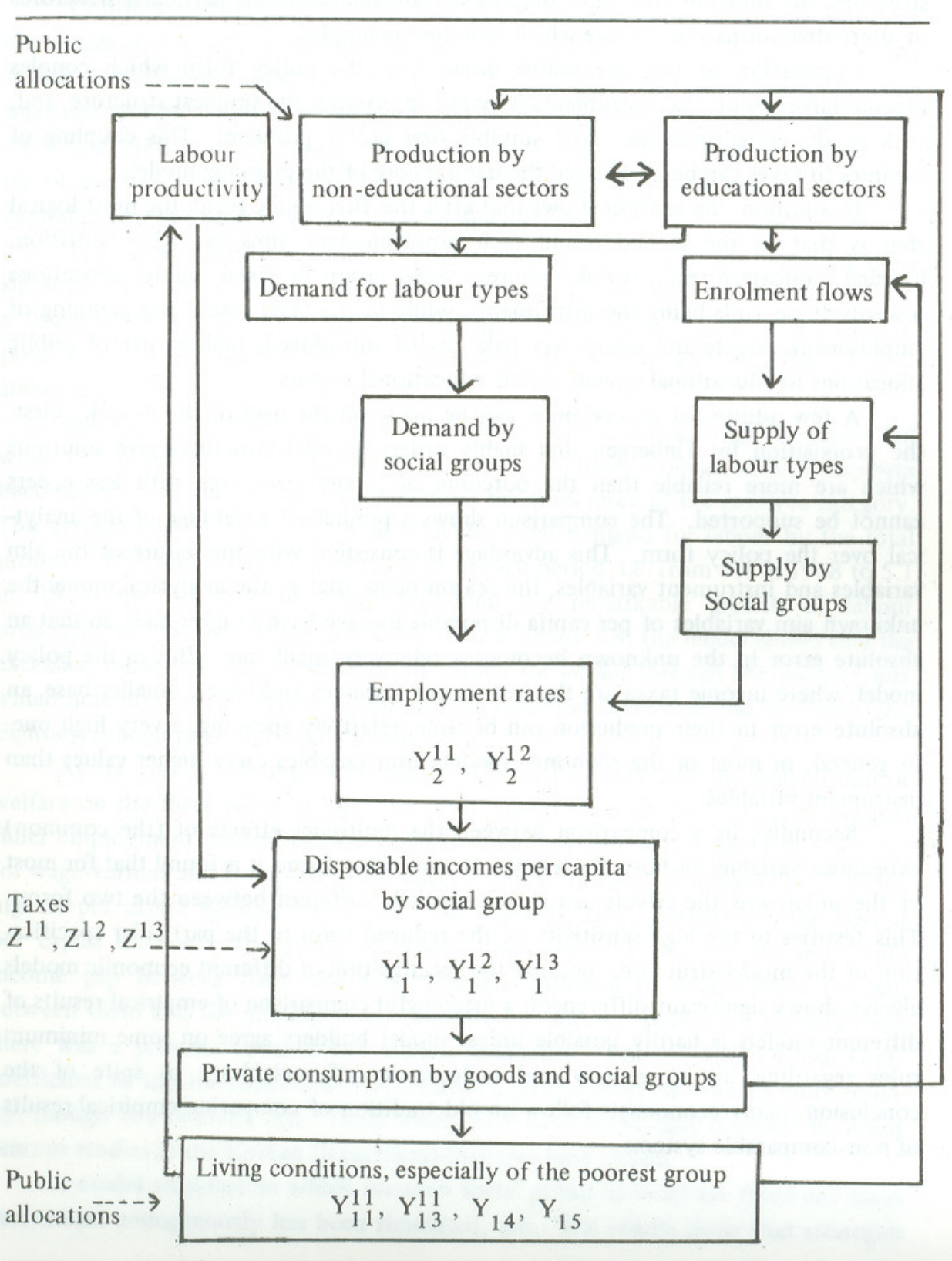


extend it later to more complex structures. In this way the analytical form of the model is adapted in a step-wise manner to the fixation of targets for more aim variables of a more complex nature until the complete policy form is approached. For our particular purpose, we shall consider that as we move to forms whose mathematical structures fall into a larger number of orders, we approach a simpler structure. By shuffling rows and columns we can triangulate the particular structures of alternative forms and observe which structure is simpler.

Application of this procedure shows that the policy form which couples income targets with tax instruments happens to produce the simplest structure, and, as a result, constitutes the most suitable first policy problem. This coupling of incomes to taxes can be considered the natural core of the planning model.

In addition, the analysis shows that after this first policy form, the most logical step is that in the second round such supplementary aims as higher nutrition, housing, education, etc., for the poorest social group be fixed, public allocations towards these ends being the instruments; while in the third round the planning of employment targets and manpower balances be introduced, making use of public allocations to educational as well as non-educational sectors.

A few additional observations can be made on the uses of the model. First, the proposition by Tinbergen that highly ordered model structures give solutions which are more reliable than the outcome of model structures with less orders cannot be supported. The comparison shows a prediction advantage of the analytical over the policy form. This advantage is consistent with the nature of the aim variables and instrument variables, the reason being that in the analytical model the unknown aim variables of per capita disposable income have a bigger base, so that an absolute error in the unknown becomes a relatively small one. But in the policy model, where income taxes are the instrument variables and have a smaller base, an absolute error in their prediction can become, relatively speaking, a very high one. In general, in most of the economic models, aim variables carry higher values than instrument variables.

Secondly, in a comparison between the multiplier effects of (the common) exogenous variables in both the analytical and policy forms it is found that for most of the unknowns the effects can be substantially different between the two forms This testifies to the high sensitivity of the reduced form to the particular specification of the model structure. Because the specification of different economic models always shows significant differences, a meaningful comparison of empirical results of different models is hardly possible unless model builders agree on some minimum rules regarding the exogeneity and endogeneity of variables. In spite of the conclusion, many economists follow an old tradition of comparing empirical results of non-comparable systems.

\section{Empirical Results of the Application}

of Model 1 to Korea

Primarily for reasons of data availability, the Korean economy was selected as a test case for Model 1. The model was econometrically estimated on the basis of data for the Sixties and employed to simulate development up to 1986.

Comparisons between solution and observed values for the Sixties show that the model represented the Korean economy fairly well. The solution gives an average annual growth rate of GNP amounting to 11.6 percent. The investment proportion increased greatly from 0.24 to 0.34 and to 0.39 over the three years viz. 1968, 1974 and 1980, which is consistent with the high growth of the GNP. On the financing of investment, it may be pointed out that the ratio of domestic savings to foreign capital inflow increases from 0.57 to 0.74 and to 0.94 .

These solutions indicate that domestic savings are increasingly becoming more significant in the financing of total investment as can be expected. Solutions showed a decreasing share of the agricultural product, an increasing share of the capitalproducing sector while the shares of the manufacturing and services sectors tend to stabilize.

Solutions also showed the share of primary enrolment in total enrolment fell while the shares of secondary and higher enrolment rose. Concurrently, manpower becomes more of the skilled type and labour becomes more of the emplyee category. The general labour coefficient which divides total demand for labour by the total product undergoes remarkable reductions in each period, i.e. from 8.4 in 1968 to 5.1 in 1974 and to. 2.7 in 1980, reflecting the remarkable growth of labour productivity. At a stable capital coefficient of about 1.8, the model shows that the excessive trend towards substitution of capital for labour through the product mix which actually existed in the Sixties would continue further in the Seventies and Eighties, though presumably at a slower pace.

As for results relating to the issues of growth, equity and the distribution of welfare on the three social groups, the employment rates develop gradually towards fuller employment, indicating that by 1980 unemployment was reduced to 5 percent for wage-earners and to 2 percent for salary earners. In 1962, employers etc. had the highest per capita income, but from 1968 onwards, salary-earners had the highest per capita income. The group of wage-earners was the poorest; the per capita income gap between them and salary-earners appeared to widen while the gap between them and the employers etc. appeared to shrink. Between 1962 and 1968 there was a progress towards less income inequality. For 1974 and 1980, Ginicoefficient of income concentration indicated a general progress towards more equality, though at a reduced rate. These results have been empirically observed in recent years as studies at the Korean Department Institute have shown.

A model structure in which for each social group incomes are fixed and taxes determined endogenously has been simulated, too. The results show that strategies 
which fix higher incomes for the poorest groups, keeping incomes of other groups unchanged, increase the government deficit by multiples of the stipulated target increase, reduce the total product and employment, and require large inflow of foreign capital to keep the balance of payments in equilibrium. These negative effects diminish remarkably if a lower income target is fixed for the population group of salary-earners and more so for employers etc. The results give support to the contention that a redistribution of income from the rich to the poor is a more efficient strategy than simply pushing the poorest up.

As far as the progress of general living conditions for the poorest group is concerned, it may be observed that the indicator of calorie consumption, $y_{11}^{11}$, is the first to reach its minimum requirements level, followed by the enrolment rate, $\mathrm{y}_{15}$, and the survival rate, $y_{14}$. The housing indicator $y_{13}^{11}$, is the most remote from its "satisfaction point".

The modelling of basic needs as defined in this model is relevant only for poor and undernourished groups. The richer classes almost always turn out to have satisfied minimum basic needs. Application of Model 1 to Korea shows that the effect of higher satisfaction of basic needs on labour productivity is significant only among the low -skilled workers and is insignificant among skilled workers.

It is significant to observe that as living conditions improve, certain social indicators become obsolute. For instance, in Korea already by 1974 the per capita calorie intake for poverty groups passed its minimum requirements. There, as elsewhere, more sophisticated indicators of the improvement in welfare are required. Since the relevance of a specific basic need is a timely phenomenon, there should be more or less a continuous search for relevant indicators whose formation and effects can be readily explained and integrated. This truth suggests that the treatment of basic needs in economic models cannot be standardized and implemented invariably.

Finally, allocations by kind to poverty groups are found to be more effective in increasing levels of nutrition, housing, etc. than a transfer which increases the income of poverty groups. This happens partly because part of the transfer leaks to other expenditure outlets, and partly because an enhanced income leads to a more expensive consumption per unit of basic needs.

\section{MODEL 2}

\section{Description of Model 2}

Although Model 1, outlined above, considers non-economic factors, yet the role it gives to the social groups can be described as 'passive' in the sense that the social groups cannot influence the development of the economy. Now we allow for an active role for social groups in the sense that these groups - or at least some of them - do influence development.
Before entering into the details of Model 2, we discuss the need for a model of this type. The foundation which economic models usually assume - including Model 1 - is characterized by a high degree of unity among different groups of the population. Members of a community voluntarily entrust the government with the function of a custodian of the general interest of the community. Once passed, the decisions of the government are respected by all members of the community Governmental institutions are sufficiently advanced, authoritative and sanctioned to carry out these decisions. All this implies that the government in such a foundation must be either sufficiently representative and/or has absolute power. However, in reality, most of the developing countries are highly heterogeneous and often contain population groups that may exercise enormous power over cthers. Governmental institutions are in their infancy and are often subjected to manipulation and chalenge by powerful pressure groups. As a result, the authority of government is limited.

Too often, uses of certain government instruments were recommended to governments of developing countries which were never implemented. On further analyses it would appear that these governments had limited authority in the implementation of many instruments. Most of the planning models tend to exaggerate the role of government in the planning of economic life and under-rate the role of the existing power structure and the private interests of pressure groups in influencing economic events. Neglect of the power structure (i.e. the distribution of power among social groups) in conventional planning models often results in unrealistic prescriptions of government aids.

The adaptation of economic models to consideration of the above sociopolitical dimension requires incorporation of two analytical distinctions:

a) the sociology of the distribution of power, and

b) the politics of the distribution of power

While the first type of analysis takes the classes of population with common interests as the major authorities in decision-making in the society at large, the second type concentrates on the composition and role of the State in influencing decisions. The interplay between both dimensions at any one time determines the framework within which one can attempt, without frustrations, an economic appraisal of alternative strategies of reform.

The first model of this type is that by Cohen $[5 ; 6] .^{7}$ In this model we distinguish four principal actors: 'peasants', 'landlords', the non-agriculturists sector, and the government. Such groups as those of peasants and landlords are assumed to behave differently. Each group is considered an independent entity which

7 In general, the introduction of political structures in economic models is in its infancy, although Adelman made some original suggestions as to their incorporation, which are mentioned in a paper by Hopkins and Van der Hoeven [10]. 
possesses its own separate institutional attitudes, production functions, saving and consumption patterns, tax and interest rates, and so forth.

When land is transferred from one group to another, it acquires the characteristic production function and value of the new owner group and ceases to function with the parameters of the previous owner group.

The groups have been formed in such a way that they minimize the variance within and maximize the variance between groups with respect to one criterion or a number of them. The criteria utilized are the parameters of the production and saving functions.

The sources of the wealth of peasants and landlords consist of (i) the value of possessed land assets, including capital and inventory, which are attached to the land, and, (ii) the value of financial assets (or liabilities). The sources of the income of peasants and landlords consist of (i) remuneration for own land assets, financial assets and labour; (ii) crop-sharing from tenancy arrangements; (iii) wages from hired farm employment; and (iv) income from the non-agricultural sector.

Several links exist between peasants and landlords: (i) transfer of land assets between the two groups; (ii) transfer of financial assets between the two groups; (iii) crop-sharing between the two groups in the case of tenancy; and (iv) a functioning of the landlord as employer and of the peasant as hired worker in the case of landlords with paid farm employment.

Model 2 considers the following links between peasants and landlords - the agricultural sector - and the non-agricultural sector: (i) financial assets and their remuneration may be transferred in either direction; (ii) the non-agricultural sector may absorb and compensate labour from agriculture, (iii) since the model is formulated within an input-output framework, it is noted that intermediate goods are delivered to all sectors while investment goods are delivered solely by the nonagricultural sector; and (iv) the final demand for goods of each sector depends on the income created in the concerned sector and the other sectors. The final demand for each sector is, therefore, dependent on the income distribution in the nation.

The government in the basic model functions explicitly as a collector of lumpsum land taxes which can be directed to investment in the agricultural and non-agricultural sectors. In addition, the government can impose, within limits, values on a number of exogenous variables or influence changes in a number of coefficients.

\section{Uses of Model 2}

The explicit specification of the existing and anticipated socio-political structure in a country opens up the way for a more fruitful economic analysis, as is demonstrated below.

The basic model treats total land, population and exports in each year, $t$, as exogenous. The basic model contains 22 endogenous variables in 20 equations and as such is underdetermined and possesses two degrees of freedom.
The major assumption in the model is that the socio-political situation at hand specifies two endogenous variables which are to be fixed exogenously, as a consequence of which a determinate model is obtained. In other words, we assume that the particular socio-political system at hand assigns exogenous values to two variables. This assignment would depend on the particular actor who moves the economy, the 'leader', and his preferences, the 'leaders welfare variables'. The remaining actors are 'followers'.

Let us take an example. In a political system characterized by feudal agrarian structure, or what we shall call a landlord-leader model, it can be realistically assumed that the sole movers and decision-makers of the economy are the group of landlords; it can further be realistically assumed that the leaders' welfare variables may be described by landlords' wealth $\left(\mathrm{W}_{2}\right)$ and landlords' income $\left(\mathrm{Y}_{2}\right)$. When both $\mathrm{W}_{2}$ and $\mathrm{Y}_{2}$ are fixed, a determinate model is obtained.

To take a different example, in a political system in which peasants are powerful enough to be the leaders, representative welfare variables of peasants are assumed to be fixed in advance. Many writers are of the opinion that such variables as the possession of more land, $\mathrm{N}_{1}$, and the reduction of financial liabilities, $\mathrm{J}_{1}$, are highly esteemed among the peasant population and, hence, could serve as their welfare variables. When both $\mathrm{N}_{1}$ and $\mathrm{J}_{1}$ are fixed, a different determinate model is obtained than that of the landlord-leader.

Yet another example is that in which the mover of the economy is the nonagricultural sector with its managers. As countries become more modernized and urbanized, the emergence of a strong urban-oriented leadership can be expected. This leadership consists usually of the intelligentsia, the industrialists, labour unions and the military. If the urban sector acts as leader, then it is one of these sub-groups, or a combination of them, through the government or in spite of the government, which dominates political developments. Predetermined variables which could represent the welfare of the urban sector should differ in accordance with the distribution of power within the urban sector. A few examples of targets of relevance for the urban sector may be mentioned. One example is a higher income of the non-agricultural wealth which is not explicitly taken in the model but can be represented by setting the agricultural financial assets $\mathbf{J}_{1}+\mathbf{J}_{2}$ at lower values, thereby increasing the financial assets of the non-agricultural sector. Targets may be fixed for the national output or national product or for agricultural and non-agricultural sectors separately.

Regarding the structures of the three versions, the starting points of the causal ordering in the landlord-leader model are the fixed targets for the income and wealth of the landlord, $\mathrm{Y}_{2}$ and $\mathrm{W}_{2}$, together they determine the savings of this group, $\mathrm{S}_{2}$, as well as their land possessions, production, and financial assets, $\mathrm{N}_{2}, \mathrm{X}_{2}$ and $\mathrm{J}_{2}$. Once these variables are known, solutions for variables of the peasant group become known, and only later solutions for the non-agricultural group become known. Both the peasants' sector and the non-agricultural sector are followers, therefore. 
The structures of peasant-leader model and the landlord-leader model can be considered almost reversals of each other. The non-agriculturalists' leadership model shows a much greater degree of interdependence and simultaneity than the other two models.

What is the role of the government in such models? In general, governments may have very complex roles. To take the simpler cases first, government may associate itself with the leader or with the followers, or remain neutral. When government associates itself with the leader, then the welfares of the leader and the government coincide. When government is otherwise associated, it attempts to influence outcomes in the direction of the follower's advantage by manipulating reform measures under its control.

Depending on the particular agrarian structure, the model considers various means of agrarian reform which differ in degrees of government control. Their use can be simulated. by manipulating certain values of variables, parameters and specifications in the following way.

1. Direct reform measures: Nationalization and direct land-redistribution laws can be simulated in the model to the extent that the government is able to impose values on the welfare variables of the leaders which are different from those that the latter desire: $\mathrm{Y}_{2}, \mathrm{~W}_{2}, \mathrm{~J}_{1}, \mathrm{~N}_{1}$.

2. Indirect reform measures: (i) Productivity-promoting measures can be simulated through appropriate manipulations of yield rates. (ii) Credit policies can be simulated through appropriate changes in the values of discount and interest rates. (iii) Land taxes can be entered through changes in tax rates. (iv) Tenure and wage regulations can be entered through changes in crop-sharing arrangements and remuneration rates. (v) New land settlements can be introduced through certain extensions in the model.

The degree of intervention and the choice of the means depend on the political leaning of the government. For example, if in a landlord-leader society the government is also dominated by landlords, there is little chance that any agrarian reform favouring peasants would take place. However, when the composition of government is not biased in the favour of landlords, government intervention can take the form of direct reform measures or indirect reform measures, although by definition the latter are politically more feasible.

Technically speaking, while the direct reform measures imply a change in the values of specific exogenous variables, the indirect reform measures are carried out by changing the values of coefficients. In substantive terms, the first runs counter to the desires of the leader group, while the second accepts them and works within their realm.

\section{Selected Results from Applications of \\ Model 2 to India, Chile and Korea}

The Model has been applied to three countries characterized by different socio-political structures. The landlord-leader model was applied to India, the peasant-leader model to Chile and the programming version of the model to Korea. The results obtained for each country are briefly discussed below.

Our classification of the Indian society in the early 1960s as a landlord-leader type would be essentially in agreement with that of Bardhan [2]. The application of the landlord-leader model to India is also consistent with the analysis made by Thorner [15], Myrdal [12] and Joshi [11]. The results reflect the path of the Indian economy fairly well, giving an annual projected growth rate of GNP of about 3.5 percent against an observed rate of about 3.3 percent over the period from 1960 to 1980 .

One important result of these projections is the almost unchanged distribution of possessed land between landlords and peasants. A second important result relates to the distribution of financial assets, which become increasingly concentrated in the hands of landlords at the cost of increasing debts of peasants. Nevertheless, the distribution of wealth among landlords and peasants, which formed a ratio of $3: 1$ in the intial year, kept about the same ratio in year 20. The ratio for income, shifted from 2.2: 1 to 2.4: 1 over the same period. The non-agricultural production and income are realistically projected to grow at higher rates than their agricultural counterparts.

A large number of policy simulations have been carried out with the purpose of determining which agrarian policies in a landlord-leader model are more effective in enhancing national welfare. It appears that judged by such criteria as reaching the highest levels of equity, land transfer programmes rank first, followed very closely by credit advances. Other simulations ranking in effectiveness in a descending order are the productivity measures, tenancy and wage regulations and higher taxation. Of course, it may not be fair to compare the direct measures of land transfer with the other indirect measure since, politically speaking, the land-transfer run is less feasible than the other runs in a landlord-led society. Among the indirect measures, it is important to emphasize, therefore, that the credit run is by far the most effective.

One interesting question is the relative performance of a combination of indirect reform measures. The results obtained for the combined simulations outrank, in a remarkable way, all other results found earlier with regard to the different criteria. For example, compared with the basic projections, the combined simulation achieves, in year 20, an additional transfer of 127 million acres of land from the rich to the poor. When one sums up the additional transfer achieved by each indirect measure separately, it amounts to only 65 million acres. This outstanding performance is due to the multiplicative effects involved in combining independent measures which are non-linearly related. 
The Chilean society represents a sensitive mixture of the landlord-leader, peasant-leader and industrialist-leader types, the balance of power having shifted from the first to the second and to the third over the last two decades. Chilean governments from 1957 onwards [Allessandri (1957 - 1964), Frei (1964 - 1970), Allende $(1970-1973)$, Pinochet $(1973-)]$ appear to play very important roles in either actively promoting these shifts in power or in simply giving legality and shape to them.

There is hardly a political issue which has drawn so much attention from politicians and laymen alike and greatly influenced Chilean events during the last two decades as the agrarian problem. And, yet Chile is highly urbanized, with about twothirds of its population living in urban areas. The non-agricultural sector accounts for 90 percent of the national product. A priori, it can be argued that agrarian solutions which are unacceptable to the industrial population have little chance of sustenance in a society with this political balance.

Applying initially the peasant-leader model to Chile, the projections show that in spite of the targeted transfer of land and the reduction of the liabilities for the benefit of peasants in the late Sixties, the income share of peasants deteriorates progressively during the 20 years. There is an improvement in the income share of rich farmers and a very substantial increase in the rich farmers' wealth. More striking are the implications of these projections for the industrial leadership. The assumed target for land transfer leads to a high accumulation of financial assets by landlords, $\mathbf{J}_{2}$. As a result, the non-agricultural sector, including the public sector, is increasingly becoming the debtor for landlords. These financial debts are projected to amount to about 40 percent of the non-agricultural income after 20 years. These are substantial debts which the non-agricultural sector has to pay back to landlords. In addition, interest payments on this non-agricultural debt cuts into the income of the non-agricultural sector. This means that the incidence of the peasant-oriented agrarian reform would fall on the non-agricultural earners. Such results would seem to us a sufficient reason why industrial leadership would not allow these specific projections to materialize.

The simulations which were carried out in consequence try to propose, adapt, and study in several steps agrarian reform measures, similar to those applied to India, which have a greater chance of achieving a future redistribution of wealth and income from rich to peasant farmers without undermining industrial interests.

The simulations pointed out that the main development contours keep their shape under alternative reformist simulations. This reflects the almost helpless role of the State in producing a coherent development pattern which satisfies the expectations of all actors. One possible scenario which was not tried is a land transfer to peasants based on a confiscation of land from landlords without compensation. Such a scenario would have relieved the non-agricultural sector from future debts and, therefore, could have gone a long way towards meeting non-agricultural interests. However, this scenario assumes revolutionary changes in the foundation of the Chilean society which do not look to be politically feasible.

In retrospect, it can be helpful to question the prospects of implementing reformist policies in the context of the particular distribution of socio-political power and values under discussion, and to reflect on the implication thereof. Under such circumstances, additional economic analysis reaches its limits. Economic analysis presupposes the existence of degrees of freedom.

Finally, we review breifly a third application of the model. In political system in which interest groups organize themselves to defend their interests we usually find that as soon as conflict arises between the welfare of opposing groups, the respective groups would organize themselves, fix their respective demands and attempt to reach a compromise agreement with each other. Usually the government participates in the bargaining with two objectives: (i) as an arbiter, and at the same time, (ii) to guarantee that compromises reached should not harm the common good.

In model form, a programming formulation is the most representative of such a socio-political system. While the interests of each group can be presented in the form of bargaining margins with lower and higher bounds, government would maximize a common aim whose benefits go to all groups, i.e. national production, subject to technical and behavioural constraints of the model and the bargaining constraints.

Accordingly, a programming version of Model 2 has been applied to Korea in an unpublished thesis by Spijker [14]. The application to Korea highlights the conflict which occurs within the landlord group regarding their higher and lower bounds of variables strategic to them, i.e. possession of land versus income. Such conflicts occur also within peasant and industrial groups. It was found that these conflicts are sensitive to government policy regarding levels of interest (credit), productivity-promoting measures and land-transfer programmes. In general, a cheap credit policy is found to facilitate more land transfer from the rich to the poor than a confiscation policy.

\section{CONCLUSIONS}

Economics is generally defined as the search for the maximum satisfaction of an objective function with the minimum use of scarce means. In practice, this search has often been operationalized in the framework of a conventional model with one actor, one aim and one mean. Such models have been grossly applied during the las three decades to the otherwise very complex structures of developing countries. The resulting situation is a confusing one.

The introduction of multiple actors in development models - in particular, different social groups - has been shown to be very essential for (i) a value-free evaluation of issues relating to the formation and distribution of welfare among 
population groups, and (ii) the realistic appraisal of alternative development policies in a situation where certain social groups are more powerful than others. By formulating aims and means in terms of social groups the modeller endeavours to eliminate a large element of value judgement from the planning tradition. As was demonstrated, group-wise distinctions of benefits, burdens and authority enhance the utility of models and provide new insights into the theory and strategy of development.

Given the foregoing, it is the opinion of the author that it should not be long before the type of models discussed in this paper would gain ground relative to the conventional model. In this respect, while Model 1 can be useful in the planning context, Model 2 should serve as an analytical tool.
Appendix

MODEL 1: (Equations)

$$
\begin{aligned}
\mathrm{V}_{\mathrm{h}} & =\sum_{\mathrm{h}^{\prime}=1}^{10} \alpha_{\mathrm{hh}^{\prime}} \mathrm{V}_{\mathrm{h}^{\prime}}+\mathrm{I}_{\mathrm{h}}+\beta_{\mathrm{h}} \mathrm{V}_{\mathrm{h}}+\sum_{\mathrm{g}=11}^{18} \gamma_{\mathrm{hg}}^{\prime} \mathrm{Z}_{\mathrm{g}} \\
& +\sum_{\mathrm{g}=11}^{15} \gamma_{\mathrm{hg}} \sum_{\mathrm{o}=11}^{13} \mathrm{C}_{\mathrm{g}}^{\mathrm{o}}+\nu_{\mathrm{h}^{\mathrm{N}}} \mathrm{N}-\mu_{\mathrm{h}} \mathrm{M}
\end{aligned}
$$

(2) $\mathrm{X}_{\mathrm{h}}=\alpha_{\mathrm{oh}} \mathrm{V}_{\mathrm{h}}$

(3) $\quad \mathrm{X}=\sum_{\mathrm{h}=1}^{10} \mathrm{X}_{\mathrm{h}}$

(4) $\quad \mathrm{I}_{10, \mathrm{t}-6}=\sum_{\mathrm{h}^{\prime}=1}^{10} \frac{\mathrm{B}_{\mathrm{hh}^{\prime}}}{6}\left(\mathrm{~V}_{\mathrm{h}^{\prime}}-\mathrm{V}_{\mathrm{h}^{\prime}, \mathrm{t}-6}\right)$

$$
\mathrm{I}_{10}-\mathrm{ZINV}=\widetilde{\beta}+\beta^{\prime} \mathrm{X}+\begin{gathered}
\mathrm{f} \text { (other explanatory variables } \\
\text { assumed exogenous) }
\end{gathered}
$$

$\mathrm{D}^{\mathrm{q}}=\widetilde{\delta}^{\mathrm{q}^{\prime}}+\delta^{\mathrm{q}^{\prime}} \sum_{\mathrm{h}=1}^{10}\left(\tilde{\delta}_{\mathrm{h}}^{\mathrm{q}^{\prime}}+\delta_{\mathrm{h}}^{\mathrm{q}^{\prime}} \mathrm{X}_{\mathrm{h}}\right)+\delta^{\mathrm{q}^{\prime \prime}}$ $\left\{\mathrm{f}\left(\mathrm{Y}_{11}^{11}, \mathrm{Y}_{13}^{11}, \mathrm{Y}_{14}\right)\right\}$ $E_{h}=\tilde{\epsilon}_{h}+\epsilon_{h} X_{h}$

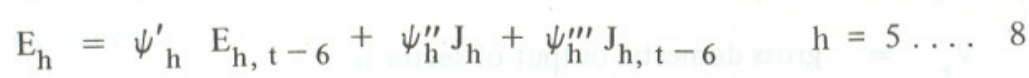
$\mathrm{S}^{\mathrm{q}}=\psi_{\mathrm{t}-6}^{\mathrm{q}} \mathrm{q}_{\mathrm{q}}^{\mathrm{q}}+\psi^{\prime \mathrm{q}} \mathrm{R}_{\mathrm{t}-12}+\sum_{\mathrm{h}=5}^{8} \psi_{\mathrm{h}}^{\mathrm{q}} \mathrm{J}_{\mathrm{h}}+\sum_{\mathrm{h}=5}^{8} \psi_{\mathrm{h}}^{\mathrm{q}} \mathrm{J}_{\mathrm{h}, \mathrm{t}-6}$

$$
\mathrm{X}^{\mathrm{o}} / \mathrm{D}^{\mathrm{o}}=\widetilde{\xi}^{\mathrm{o}}+\xi^{\mathrm{o}}\left(\mathrm{X} / \mathrm{D}^{\mathrm{o}}\right)-\xi^{\mathrm{o}^{\prime}}\left(\mathrm{S}^{\mathrm{o}} / \mathrm{D}^{\mathrm{o}}\right)
$$

(13) $\quad \mathrm{X}=\sum_{\mathrm{o}=11}^{13} \mathrm{X}^{\mathrm{O}}+\mathrm{ZIND}$ 


$$
\left(C_{11}^{11}+Z_{11}\right) /\left(\pi^{11} P Y_{11}^{11}\right)=\check{\phi}_{11}^{11}+\phi_{11}^{11} Y_{1}^{11}
$$$$
\left(\mathrm{C}_{13}^{11}+\mathrm{Z}_{13}\right) /\left(\pi^{11} \mathrm{PY}_{13}^{11}\right)=\widetilde{\phi}_{13}^{11}+\phi_{13}^{11} \mathrm{Y}_{1}^{11}
$$$$
\left(\sum_{\mathrm{o}=11}^{13} \mathrm{C}_{14}^{\mathrm{o}}+\mathrm{Z}_{14}\right) /(\mathrm{P})\left(\mathrm{Y}_{14}\right)=\tilde{\phi}_{14}+\phi_{14}\left({\underset{\mathrm{o}}{\Sigma}=11}_{\sum_{11}^{13}} \mathrm{Y}^{\mathrm{o}} / \mathrm{P}\right)
$$

$$
\mathrm{L}^{\mathrm{q}}=\lambda^{\mathrm{q}} \mathrm{Y}_{14}
$$

$$
\mathrm{L}_{\mathrm{h}}=\lambda_{\mathrm{h}} \mathrm{Y}_{14}
$$$$
\mathrm{h}=5 \ldots 8
$$

$$
\mathrm{P}=\psi \mathrm{P}_{\mathrm{t}-6}+\psi^{\prime} \mathrm{R}
$$

$$
\mathrm{Y}_{15}=\mathrm{E}_{5} / \mathrm{P}
$$

$$
\mathrm{M}+\sum_{\mathrm{h}=1}^{10} \mu_{\mathrm{h}^{\prime}} \mathrm{V}_{\mathrm{h}}=\mathrm{N}+\mathrm{F}
$$

$$
\sum_{\mathrm{o}=11}^{13} \mathrm{Z}^{\mathrm{o}}+\mathrm{ZIND}+\mathrm{BUGF}+\sum_{\mathrm{g}=1}^{18} \mathrm{Z}_{\mathrm{g}}+\mathrm{ZINV}
$$

\section{MODEL 1: Symbols}

\section{$\mathrm{V}_{\mathrm{h}}=$ gross domestic output of sector $\mathrm{h}$}

$\mathrm{I}_{10}=$ gross fixed capital formation produced and delivered by capital producing sector 10

$\sum_{\mathbf{0}} \mathrm{C}_{\mathrm{g}}^{\mathrm{o}}=$ sum of private consumption of good $\mathrm{g}$ by all social groups o

$\mathrm{M}=$ total imports of competitive goods

$\mathrm{N}=$ total exports of goods and services, exogenous

$\mathrm{Z}_{\mathrm{g}} \quad=$ government consumption expenditure on good or service g, exogenous

$\mathrm{X}_{\mathrm{h}}=$ gross value added of sector $\mathrm{h}$

$\mathrm{X}=$ gross domestic product at market prices
$\mathrm{ZINV}=$ government investment expenditure; exogenous

$\mathrm{D}^{\mathrm{q}}=$ employment of manpower with skill type q

$\mathrm{E}_{\mathrm{h}}=$ total enrolments in educational level $\mathrm{h}, \mathrm{h}=5 \ldots 8$

all $\psi_{\mathrm{h}}=\mathrm{f}$ (rates of graduation, dropouts, survival by educational level i.e. $\mathrm{L}_{\mathrm{h}}$ )

$\mathrm{J}_{\mathrm{h}}=$ new entrants in educational level $\mathrm{h}, \mathrm{h}=5 \ldots 8$

all $\psi^{\mathrm{q}}, \psi_{\mathrm{h}}^{\mathrm{q}}=\mathrm{f}$ (rates of participation, graduation, dropouts, retirement, survival by manpower skills i.e. $\mathrm{L}^{\mathrm{q}}$ )

$\mathrm{S}^{\mathrm{q}}=$ Supply of manpower with skill type $\mathrm{q} \cdot \mathrm{R}_{\mathrm{t}-12}=$ lagged births, exogenous

$\mathrm{D}^{\mathrm{o}}=$ Employment of labour of social group o

$\mathrm{S}^{\mathrm{O}}=$ Supply of labour of social group o

$\mathrm{X}^{\mathrm{O}}=$ Gross income of social group o

$\mathrm{ZIND}=\quad$ term standing for the gross government income from property and entrepreneurship at factor cost plus indirect taxes less subsidies, less net factor income from the rest of the world at market prices; exogenous

$\mathrm{Y}^{\mathrm{O}}=$ disposable income of social group o

$\mathrm{Z}^{\mathrm{O}}=$ net direct transfers to government from social group o, exogenous

$\pi^{\mathrm{o}}=$ proportion of population of social group $\mathrm{o}, \mathrm{P}=$ total population all $\psi=\mathrm{f}\left(\mathrm{Y}_{14}\right)$

$\mathrm{F}=$ net foreign capital inflow

BUGF $=$ budgetary deficit 
MODEL 2: (Equations)

(Equations Relating to Peasant Group)

(1) $\quad \mathrm{X}_{1}=\pi_{1}\left(1+\pi_{1}^{\prime}\right)^{\mathrm{t}} \mathrm{N}_{1}$

(2) $\mathrm{I}_{1}=\mathrm{K}_{1} \pi_{1} \pi_{1}{ }^{\prime} \mathrm{N}_{1}$

(3) $\mathrm{W}_{1}=\frac{\delta_{1} \beta_{1}\left(1+\iota_{1}\right)}{\iota_{1}-\pi_{1}^{\prime}} \mathrm{X}_{1}-\frac{\tau_{1}\left(1+\iota_{1}\right)}{\iota_{1}}-\mathrm{N}_{1}+\mathrm{J}_{1}$

(4) $\quad \mathrm{Y}_{1}=\frac{1}{1-\eta_{1}}\left\{\left(\alpha_{1}+\beta_{1}\right) \mathrm{X}_{1}-\tau_{1} \mathrm{~N}_{1}+\left(\lambda_{21} \alpha_{2}+\right.\right.$ $\left.\left.\nu_{21} \beta_{2}\right) X_{2}+\iota_{1}^{\prime} J_{1}\right\}$

(5) $\mathrm{S}_{1}=\sigma_{1}+\sigma_{1}^{\prime} \mathrm{Y}_{1}-\sigma_{1}^{\prime \prime} \mathrm{W}_{1}$

(6) $\mathrm{L}_{1}=\mathrm{U}_{1}+\mu_{1} \mathrm{X}_{1}+\left\{\frac{\lambda_{21} \alpha_{2}+\nu_{21} \beta_{2}}{\rho_{\mathrm{a}}}\right\} \mathrm{X}_{2}$ (Equations Relating to Landlord Group)

(7) $\quad \mathrm{X}_{2}=\pi_{2}\left(1+\pi_{2}^{\prime}\right)^{\mathrm{t}} \mathrm{N}_{2}$

(8) $\quad \mathrm{I}_{2}=\mathrm{k}_{2} \pi_{2} \pi_{2}^{\prime} \mathrm{N}_{2}$

(9) $\mathrm{W}_{2}=\frac{\delta_{2} \beta_{2}\left(1+\iota_{2}\right)}{\iota_{2}-\pi_{2}^{\prime}} \mathrm{X}_{2}-\frac{\tau_{2}\left(1+\iota_{2}\right)}{\iota_{2}} \mathrm{~N}_{2}+\mathrm{J}_{2}$

(10) $\quad \mathrm{Y}_{2}=\frac{1}{1-\eta_{2}}\left\{\left(\left(1-\lambda_{21}\right) \alpha_{2}+\left(1-\nu_{21}\right) \beta_{2}\right) \mathrm{X}_{2}-\tau_{2} \mathrm{~N}_{2}+\right.$ $\left.\iota_{2}^{\prime} \mathrm{J}_{2}\right\}$

(11) $\mathrm{S}_{2}=\sigma_{2}+\sigma_{2}^{\prime} \mathrm{Y}_{2}-\sigma_{2}^{\prime \prime} \mathrm{W}_{2}$

(12) $\mathrm{L}_{2}=\mathrm{U}_{2}+\mu_{2} \mathrm{X}_{2}-\left\{\frac{\lambda_{21} \alpha_{2}+\nu_{21} \beta_{2}}{\rho_{\mathrm{a}}}\right\} \mathrm{X}_{2}$

(Equations Relating to Agriculture and Non-agriculture)
$\mathrm{X}_{\mathrm{h}}=$ gross production $\mathrm{h}=1,2,3$

$\mathrm{Y}_{\mathrm{h}}=$ disposable income, $\mathrm{h}=1,2,3$

$\alpha_{\mathrm{h}}=$ proportion of wages in gross production, $\mathrm{h}=1,2$

$\beta_{\mathrm{h}}=$ proportion of rent in gross production, rent is defined widely to include remuneration to land and capital, $\mathrm{h}=1,2$

$\gamma_{\mathrm{h}}^{\prime} \gamma_{\mathrm{h}}^{\prime}=$ intercept, and propensity to consume agricultural goods by group $\mathrm{h}$ from total consumption of group $\mathrm{h}, \mathrm{h}=1,2,3$

$\delta_{\mathrm{h}}=$ factor accounting for discrepancy between owner's valuation and market value of land, $\mathrm{h}=1,2$

$\eta_{\mathrm{h}}=$ share of non-agricultural income of group $\mathrm{h}$ in total income of group $\mathrm{h}$, $\mathrm{h}=1,2$

$\iota_{\mathrm{h}}=$ rate of discount used by a group for discounting its future income $\mathrm{h}=1$, 2

$i_{\mathrm{h}}=$ rate of interest applying to borrowings or lendings of a group, $\mathrm{h}=1,2$

$\mathrm{k}_{\mathrm{h}}=$ incremental capital output ratio, $\mathrm{h}=1,2,3$

$\mathrm{k}_{\mathrm{h}}^{\prime}=$ public investment per acre, $\mathrm{h}=1,2$

$\lambda_{\mathrm{hh}^{\prime}}=$ proportion of wages of sector $\mathrm{h}$ which is transferred to sector $\mathrm{h}^{\prime}, \mathrm{h}, \mathrm{h}^{\prime}$ $=1,2$

$\mu_{\mathrm{h}} \quad=$ labour-output ratio, $\mathrm{h}=1,2$

$\nu_{\mathrm{hh}^{\prime}}=$ proportion of rent of sector $\mathrm{h}$ which is transferred to sector $\mathrm{h}, \mathrm{h}^{\prime}=1,2$

$\pi_{\mathrm{h}}, \pi_{\mathrm{h}}{ }^{\prime}=$ initial production per acre, and its growth rate, $\mathrm{h}=1,2$

$\rho_{\mathrm{a}} \quad=$ wage rate in agriculture

$\sigma_{\mathrm{h}}, \sigma_{\mathrm{h}}^{\prime}, \sigma_{\mathrm{h}}^{\prime \prime}=$ intercept propensity to save from income, and propensity to save from wealth, $\mathrm{h}=1,2,3$

$$
\mathrm{N}_{\mathrm{a}}=\mathrm{N}_{1}+\mathrm{N}_{2}
$$




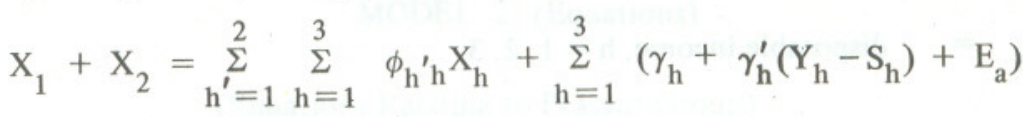

$$
\begin{gathered}
\mathrm{X}_{3}=\sum_{\mathrm{h}=1}^{3} \phi_{\delta \mathrm{h}} \mathrm{X}_{\mathrm{h}}+\sum_{\mathrm{h}=1}^{3}\left(-\gamma_{\mathrm{h}}+\left(1-\gamma_{\mathrm{h}}^{\prime}\right)\left(\mathrm{Y}_{\mathrm{h}}-\mathrm{S}_{\mathrm{h}}\right)\right) \\
+\mathrm{I}_{1}+\mathrm{I}_{2}+\mathrm{k}_{1}^{\prime} \mathrm{N}_{1}+\mathrm{k}_{2}^{\prime} \mathrm{N}_{2}+\mathrm{I}_{3}+\mathrm{E}_{3}
\end{gathered}
$$

$$
\begin{aligned}
\mathrm{Y}_{3}=\mathrm{X}_{3} & -\sum_{\mathrm{h}=1}^{3} \phi_{\mathrm{h}_{3}} \mathrm{X}_{3}-\eta_{1} \mathrm{Y}_{1}-\eta_{2} \mathrm{Y}_{2}-\iota_{1}^{\prime} \mathrm{J}_{1}-\iota_{2}^{\prime} \mathrm{J}_{2} \\
& +\tau_{1} \mathrm{~N}_{1}+\tau_{2} \mathrm{~N}_{2}
\end{aligned}
$$

(18) $\quad \mathrm{S}_{3}=\sigma_{3}+\sigma_{3}^{\prime} \mathrm{Y}_{3}$

(19) $\quad \mathrm{I}_{3, \mathrm{t}-1}=\mathrm{k}_{3}\left(\mathrm{X}_{3}-\mathrm{X}_{3, \mathrm{t}-1}\right)$

(20) $\mathrm{E}=\mathrm{E}_{\mathrm{a}}+\mathrm{E}_{3}$

\section{MODEL 2 : Symbols}

$\mathrm{E}_{\mathrm{a}}, \mathrm{E}_{3}, \mathrm{E}=$ balance of exports less imports for the agricultural and non-agricultural sectors and for the whole economy, respectively E, which can also be described as foreign capital flow, is exogenous

$=$ gross investment purchases by sector $\mathrm{h}, \mathrm{h}=1,2,3$

$\mathrm{J}_{\mathrm{h}} \quad=\quad$ financial assets, $\mathrm{h}=1,2$

$\mathrm{L}_{\mathrm{h}}=$ population of group $\mathrm{h}$, which is taken to be exogenous, $\mathrm{h}=1,2$

$\mathrm{N}_{\mathrm{h}}, \mathrm{N}_{\mathrm{a}}=$ land acreage possessed by group $\mathrm{h}, \mathrm{h}=1,2$; and the total agricultural land acreage, which is taken to be exogenous

$\mathrm{S}_{\mathrm{h}} \quad=$ savings, $\mathrm{h}=1,2,3$

$\mathrm{U}_{\mathrm{h}}=$ unutilized population of group $\mathrm{h}, \mathrm{h}=1,2$

$\mathrm{W}_{\mathrm{h}}=$ wealth, $\mathrm{h}=1,2$ $\tau_{\mathrm{h}} \quad=\quad$ land tax per acre, $\mathrm{h}=1,2$

$\phi_{\mathrm{hh}}=$ inputs of intermediate goods from sector $\mathrm{h}$ to sector $\mathrm{h}^{\prime}$ per unit of output of sector $\mathrm{h}^{\prime}, \mathrm{h}, \mathrm{h}^{\prime}=1,2,3$
Symbols. The right hand lower index $\mathrm{h}$ refers to actors in the model, specifically, 1 refers to peasants, 2 to landlords, and 3 to the non-agricultural sector, while the letter a is used for agriculture as a whole.

Greek letters indicate parameters. Latin letters indicate variables. Unless otherwise
all constant prices. 


\section{REFERENCES}

1. Adelman, I. and S. Robinson. Income Distribution Policy in Developing Countries: A Case Study of Korea. Stanford: Stanford University Press. 1978.

2. Bardhan, P.K. Redistribution with Growth, Some country Experience. In H. B. Chenery et al. Redistribution with growth. London: Oxford University Press. 1974.

3. CCRP. Model SERES. Bogota: Corporacion Centro Regional de Poblacion. 1975.

4. Cohen, S. I. Production, Manpower and Social Planning. Rotterdam: Rotterdam University Press. 1975.

5. Cohen, S. I. “A Social-Economic Development Model: Korean Application”. Economic Review. Vol. XI, No. 1. 1977.

6. Cohen, S. I. "Development Models with Different Decision-Makers". In Proceedings of Conference: Future Research, Planning and Decision Making, Polish Academy of Sciences, Warsaw, Jablonowa. April 1977.

7. Cohen, S. I. Agrarian Structures and Agrarian Reform. Boston: Kluwer. 1978.

8. Correa, H. and K. A. Khan. A Simulation Model for Planning Population Growth, Health, Nutrition, Education Economic Development. Pittsburgh: University of Pittsburgh. 1974.

9. Fisher, F., et al. "Price and Output Aggregation in the Brookings Econometric Model”. In J. Duesenberg, et al. (eds.), The Brookings Quarterly Econometric Model of the U.S. Amsterdam: North - Holland Publishing Company. 1965.

10. Hopkins, M., and R. Van der Hoeven. Economic and Social Factors in Development: A Socio-economic Framework for Basic Needs Planning. (Working paper) Geneva: ILO. 1979.

11. Joshi, P.C. Land Reforms in India. Poona. 1975.

12. Myrdal, G. Asian Drama: An Inquiry into the Poverty of Nations. New York: Pantheon. 1968.

13. Rodgers, G., et al. BACHUE Philippines, Population, Employment and inequality. Farnborough, Hants. (UK): Sason House. 1978.

14. Spijker, H. "Landownership and Power Structure". Unpublished Master's thesis (in Dutch), Erasmus University, Rotterdam. 1977.

15. Thorner, D. The Agrarian Prospect in India. Delhi: University Press. 1956. 16. United Nations. Preliminary Report of Targets of Social Development. New York: ECOSOC. 1966. 